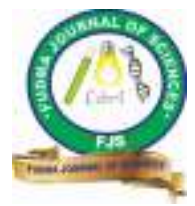

FUDMA Journal of Sciences (FJS)

ISSN online: $2616-1370$

ISSN print: 2645 - 2944

Vol. 4 No. 3, September, 2020, pp $148-153$

DOI: https://doi.org/10.33003/fjs-2020-0403-356

\title{
SYNTHESIS, CHARACTERIZATION AND PHOTOACTIVITY EVALUATION OF NITROGEN DOPED TITANIUM DIOXIDE ON METHYLENE BLUE DYE DEGRADATION.
}

\author{
${ }^{* 1}$ Moses Titus Yilleng, ${ }^{2}$ Moses Sunday, ${ }^{1}$ Doctor Stephen \\ ${ }^{1}$ Chemistry Department, Kaduna State University, Kaduna State, Nigeria \\ ${ }^{2}$ Chemistry Department, Federal Polytechnic, Kaura Namoda, Zamfara State, Nigeria \\ *Corresponding Author's Email: yilleng.moses@kasu.edu.ng
}

\begin{abstract}
Titanium dioxide has proven to be one of the most promising heterogeneous catalyst. This work explores the photocatalytic activity of modified titanium dioxide. Nitrogen was incorporated into mesoporous $\mathrm{TiO}_{2}$ using

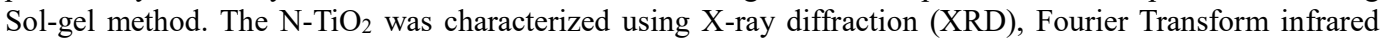
spectroscopy (FTIR), Transmission electron microscopy (TEM), Scanning electron microscopy (SEM) thermogravimetric analysis (TGA), and U-Vis diffuse reflectance spectroscopy (DRS). $1 \% \mathrm{wtN}-\mathrm{TiO}_{2}$ expresses the highest photoactivity in UV light compared to $3 \% \mathrm{wtN}-\mathrm{TiO}_{2}$ and $5 \% \mathrm{wt} \mathrm{N}-\mathrm{TiO}_{2}$ respectively. The photodegradation efficiency of the catalyst follows the following trend $1 \% \mathrm{wtN}-\mathrm{TiO}_{2}>3 \% \mathrm{wtN}-\mathrm{TiO}_{2}>5 \% \mathrm{wtN}-$ $\mathrm{TiO}_{2}>\mathrm{PURE}-\mathrm{TiO}_{2}$. The results obtained from the kinetics investigation shows the following trends $1 \% \mathrm{wtN}$ -

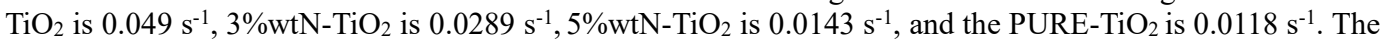
consistency in the rate constant values of the phodegradation of methylene blue; it clearly showed that the reaction follows a pseudo-first order kinetics.
\end{abstract}

Keywords: Photocatalyst, methylene blue, $\mathrm{N}-\mathrm{TiO}_{2}$, degradation, nanomaterials.

\section{INTRODUCTION}

The energy that the Earth receives from the Sun is about $3 \times 10^{24}$ joules a year, which is nearly 10,000 times more than the global energy consumption (Chao, 2014). The photocatalytic reactions may occur homogeneously or heterogeneously, but heterogeneous photocatalysis is by far more intensively studied in recent years because of its potential use in a variety of environmental and energy-related applications as well as in organic syntheses, which include disinfection of water and air, mineralization of organic pollutants, production of renewable fuels, and organic synthesis. Heterogeneous photocatalysis using semiconductors such as titanium dioxide $\left(\mathrm{TiO}_{2}\right)$ has been one of the most widely studied. The favorable combination of electronic structure, light absorption properties, charge transport characteristics, and excited lifetimes of some semiconductors has made possible its application as photocatalyst (Serway and Jewette, 2018; Shan et al., 2008).

When the energy of incident light is larger than the band gap, electron will be excited from the valence band to the conduction band and leave a positive charge, so-called a "hole", at the valence band which can obtain electrons (Parker, 1984). Most of the separated electrons and holes recombine to release energy in the heat form; only a few can reach the surface and have the capacity to drive the reaction. To enhance the photocatalysis, electron-hole pair recombination must be restricted. This can be achieved by trapping a photogenerated electron, a photogenerated hole or both of them. This process is shown in Figure 1.

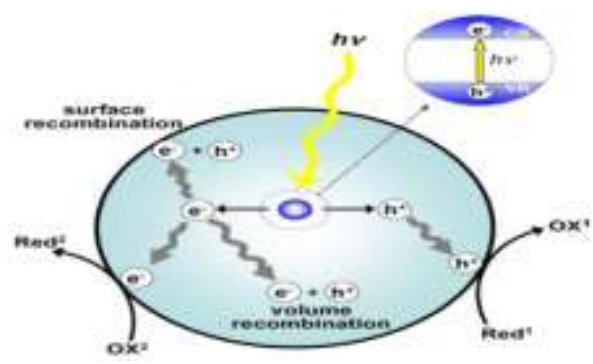

Fig 1. Photocatalytic reaction occurring on photoactivated $\mathrm{TiO}_{2}$ particle (Mahvi et al., 2009)

To overcome the above-mentioned drawback in visible light utilization, many researchers have made great efforts to modify the band structure of $\mathrm{TiO}_{2}$ so as to shift its absorption edge towards the visible light region (Zhang, et al., 2013; Yilleng et $a l ., 2018)$. One route for sensitizing $\mathrm{TiO}_{2}$ to visible light so as to permit the use of the main part of the solar spectrum and also forming charge traps to keep electron-hole pairs separate is by doping pure $\mathrm{TiO}_{2}$ with foreign ions (Nishizawa et al., 2014). The doping of $\mathrm{TiO}_{2}$ is currently attracting considerable interest as a promising route to extend the optical absorption of this material to visible spectral region. One promising approach to synthesizing visible light active photocatalyst is the substitution of titanium by transition metals, such as $\mathrm{V}, \mathrm{Cr}, \mathrm{Ni}$, or $\mathrm{Fe}$, and so on (Borgarello et al., 1982; Klosek and Raftery, 2001). However, most of these metal-doped $\mathrm{TiO}_{2}$ do not show longterm stability or do not have sufficient activities for wide range of applications. Another promising approach is the doping of non-metal atoms, such as N, S, or C (Asahi et al., 2001; Zhao et al., 2008). The non-metal atoms doping has been reported to be 
more effective for the band gap narrowing of $\mathrm{TiO}_{2}$ than transition metal doping (Chen et al., 2007; Choi et al., 1994) That is because their impurity levels are near the valence band edge of $\mathrm{TiO}_{2}$. Therefore, they do not act as charge carriers and their roles as recombination centers are minimized compared to the metal doping (Wang and Lewis, 2005; Chen et al., 2007; Choi el at., 1994). Although the photoactivity of titania modified with carbon was attributed to the formation of C-doped $\mathrm{TiO}_{2}$ depicts the formation, interstitial carbonate-doped $\mathrm{TiO}_{2}$ and highly condensed coke-like carbon containing $\mathrm{TiO}_{2}$ etc which acts as electron sink to reduce the rate of electron recommunication (Wang and Lewis, 2005; Chen et al., 2007; Choi et al., 1994; Zabek and Kisch, 2010).

So many researchers begin to further investigate and use different kinds of method to prepare nitrogen-doped $\mathrm{TiO}_{2}$ for example, Asahi et al (2001) prepared $\mathrm{N}^{-\mathrm{TiO}_{2}}$ material by calcination of the commercial $\mathrm{TiO}_{2}$ at ammonia-argon atmosphere; Bang in 2005 prepared nitrogen-doped titanium dioxides using the atmospheric microwave and plasma (Hong et al., 2005); Suda et al., (2005) used the method of pulsed laser deposition to prepare $\mathrm{N}^{-\mathrm{TiO}_{2}}$ material. Besides, it is also observed that the state of $\mathrm{N}$ in Titania and its effectiveness in extending the light absorption edge depend upon the way it is introduced through several preparation methods/techniques (Suda et al., 2005; Viswanathan and Krishna, 2012).

Methylene blue (MB) is a cationic dye, used extensively for dying cotton, wool and silk. The risk of the existence of this dye in waste water may be arisen from the burns effect of eye, nausea, vomiting and diarrhea (Lang et al., 2009; Hosseinnia and Keyanpour-rad, 2010). Environmental pollution on a global scale, as well as the lack of sufficient clean energy sources, have drawn much attention to the need for developing ecologically clean chemical technology, materials, and process (Coro et al., 2005; Vazquez et al., 2010). Cationic dyes not only impart colours to water sources but also damage living organisms by stopping the re-oxygenation capacity of water, blocking sunlight, and therefore disturbing the natural growth activity of aquatic life (Song et al., 2010; Wang, 2008). The aim of this investigation was to use sol immobilization method to synthesis $\mathrm{N}-\mathrm{TiO}_{2}$ with enhance morphology and surface properties whose photoactivity was evaluated using methylene blue dye. and a representative evaluation of their photoactivity on methylene blue dye.

\section{EXPERIMENTAL}

\section{Preparation of the photocatalyst $\left(\mathrm{N}-\mathrm{TiO}_{2}\right)$}

The $\mathrm{N}^{-\mathrm{TiO}_{2}}$ catalyst was prepared base on the method of described by Chakraborty and Roychudhury (2013). To prepare the $\mathrm{N}^{-\mathrm{TiO}_{2}}, 0.293 \mathrm{~g}$ of $\mathrm{P} 25$ Degussa was added into $100 \mathrm{ml}$ ammonia solution. To enhance homogeneous dispersion, the solution in a conical flask was placed on a magnetic stirrer at 5 revolution per minute, for 1 hour. the solution was placed in an oven and heated at $150^{\circ} \mathrm{C}$ for $24 \mathrm{~h}$. The resulting solution obtained was then cool to $26^{\circ} \mathrm{C}$. Afterward the dried solid obtained was subjected for calcination at $600^{\circ} \mathrm{C}$ for 2 hours. The synthesized powder of nitrogen doped titanium dioxide, was collected and labeled as $1 \% \mathrm{~N}-\mathrm{TiO}_{2}$. The same procedure was

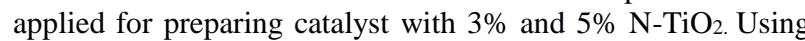
$0.898 \mathrm{~g}$ and $1.528 \mathrm{~g}$ respectively into the same $100 \mathrm{~cm}^{-3}$ volume of the ammonia. The P25 precursor sample was also treated under the same condition using absolute ethanol as a solvent instead of ammonia and also labelled as pure- $\mathrm{TiO}_{2}$.

\section{Catalyst characterization}

Characterization of the synthesized photocatalyst FTIR analysis was done using the SHIDMAZU FT-IR spectrophotometer. XRD analysis were carried out on a Philips X'Pert3 Analytical diffractometer, using $\mathrm{Cu} \mathrm{K} \alpha$ radiation with $\lambda=0.15406 \mathrm{~nm}$. The Crystalline structure and External morphology of the catalyst was viewed using Quanta Scanning Electron Microscope FEI Quanta 250. The measurement of transmission electron microscopy (TEM) was carried out on a FEI Tecnai ${ }^{\mathrm{TM}}$ F20 Transmission electron microscopes (TEMs) at 200kV. The optical characterization of the photocatalyst was carried out using Diffuse Reflectance UV-vis spectrophotometer equipped with a Harrick Praying Mantis TM diffuse reflection accessory used for solid samples (Perkin Elmer Lambda 6505) in the wavelength range from 250 to $800 \mathrm{~nm}$ with scanning speed of $300 \mathrm{~nm} / \mathrm{min}$. The ultraviolet visible diffuse reflectance spectra (UV-vis DRS) of the as-synthesized samples were recorded on a UVX Radiometer (UVP Inc., Upland CA) equipped with a UVX-36 long wave sensor equipped with an integrating sphere and using $\mathrm{BaSO}_{4}$ as the reference. The thermogravimetric analysis was performed using Mettler-Toledo TGA/DSC I STAR instrument with heating rate of $20^{\circ} \mathrm{C} / \mathrm{min}$ in nitrogen $\left(\mathrm{N}_{2}\right)$ atmosphere.

Evaluation of the photocatalytic activity of the catalyst by degradation of the methylene blue

During the photocatalytic degradation of methylene blue (MB), $0.20 \mathrm{~g}$ of the $\mathrm{N}-\mathrm{TiO}_{2}$ photocatalyst was placed into $100 \mathrm{ml}$ solution of $2 \times 10^{-5} \mathrm{molL}^{-1}$ of MB in a $250 \mathrm{ml}$ conical flask, the MB solution and the catalyst was kept in the dark for $30 \mathrm{~min}$ before taken to the photoreactor. The absorbance of the MB was measured before irradiation and after every 20 minutes interval.

At each 20 minutes of irradiation, $10 \mathrm{ml}$ of the solution would be taken out of the conical flask and centrifuged at the rate of $4000 \mathrm{rpm}$ for easier isolation and removal of the used photocatalyst, then the absorbance was measured. The absorbance of the supernatant is a function of the dye concentration estimation after every 20 minutes. While the used catalyst was then characterized using FT-IR analysis after the complete 80 minutes of irradiation in the photoreactor. This is to help identified the presence of functional group corresponding to the MB fragment, which is an indicator for photodegradation activity.

\section{RESULT AND DISCUSSION \\ FTIR measurement}

The FTIR result of unused $1 \% \mathrm{~N}-\mathrm{TiO}_{2}$ showed Ti-O-Ti stretching observed at $401 \mathrm{~cm}^{-1}, 524.66 \mathrm{~cm}^{-1}, 601.81 \mathrm{~cm}^{-1}, 671.25 \mathrm{~cm}^{-1}$, and $717.54 \mathrm{~cm}^{-1}$, while $879.57 \mathrm{~cm}^{-1}$ band corresponding to Ti-O vibrational stretching. Both as a function of the incidence angle and of the heat-treatment temperature resulting from the muffle furnace. A band was observed at $1627.97 \mathrm{~cm}^{-1}$ which is associated with $\mathrm{N}-\mathrm{H}$ bend of the ammonia molecule. N-H asymmetric stretching vibration was observed at $3402.54 \mathrm{~cm}^{-1}$. At $3688.02 \mathrm{~cm}^{-1}, \quad 3757.46 \mathrm{~cm}^{-1}$ and $3865.48 \mathrm{~cm}^{-1}$ bands correspond to $\mathrm{O}-\mathrm{H}$ stretch of hydrogen bonded of water molecule in the ammonia solution. While that of used $1 \% \mathrm{~N}-\mathrm{TiO}_{2}$ after the 80 minutes irradiation in addition to common peaks to 
that of the un-use with $\mathrm{C}-\mathrm{N}$ stretching of an aliphatic amine was observed at $1018.45 \mathrm{~cm}^{-1}$ and another stretching was observed at $1419.66 \mathrm{~cm}^{-1}$ due to $\mathrm{C}-\mathrm{C}$ in the aromatic structure. C-H stretching of the methyl groups at $2924.18 \mathrm{~cm}^{-1}$. While at $3371.68 \mathrm{~cm}^{-1}$ and $3495.13 \mathrm{~cm}^{-1}$ belongs to N-H stretching of the ammonia solution. At band $3880.91 \mathrm{~cm}^{-1}$ belongs to $\mathrm{O}-\mathrm{H}$ stretch of hydrogen bonded of water molecule in the ammonia solution XRD measurement

The XRD patterns of the as-prepared $1 \% \mathrm{~N}-\mathrm{TiO}_{2}$ samples were shown in Fig.3, which contained both anatase and rutile phase, with anatase peaks predominantly re-occurring with increase in intensities. Obviously, the XRD patterns revealed that doping with nitrogen has the potential of restraining. the transformation from anatase to rutile and brookite. The crystallinity was sharply improved by doping with nitrogen, which was beneficial to the enhancement of photocatalytic activity (Xie et al., 2010). The crystallite size was calculated using Scherrer's formula (Zang et al., 2000) according to the full width at half-maximum of the diffraction pattern.

$$
D=K \lambda / \beta \cos \theta
$$

Where $\mathrm{D}$ is the average crystal size of the sample, $\lambda$ the X-ray wavelength (1.54056 $\AA$ ), $\beta$ the full-width at half maximum (FWHM) of the diffraction peak (radian), $\mathrm{K}$ is a coefficient (0.89) and $\theta$ is the diffraction angle at the peak maximum.

The as-calculated average crystal sizes of the $1 \% \mathrm{~N}-\mathrm{TiO}_{2}$ materials were $10.40 \mathrm{~nm}$. The difference in crystallite size can be ascribed to the introduction of $\mathrm{N}$ doping. Furthermore, the $\mathrm{N}$ doped sample exhibited typical structure of $\mathrm{TiO}_{2}$ crystal without any detectable peak due to Nitrogen. The reason could be due to the fact that the nitrogen species have moved into either the interstitial positions or the substitutional sites of the $\mathrm{TiO}_{2}$ crystal structure.

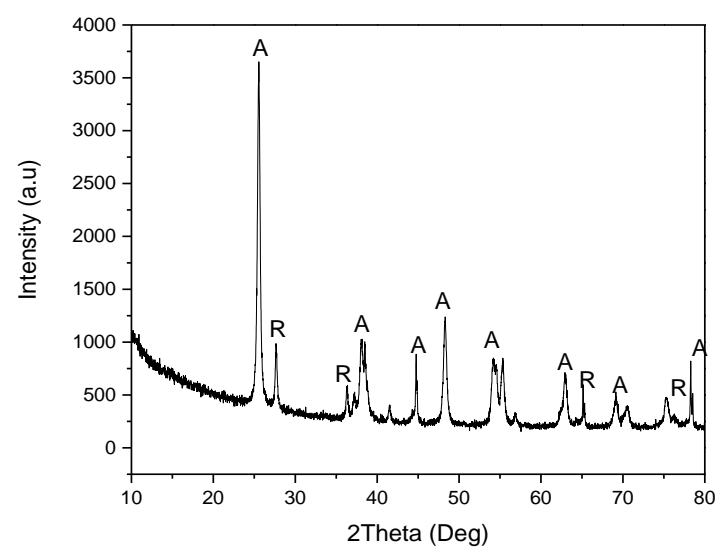

Fig. 3 XRD pattern of $1 \% \mathrm{wtN}-\mathrm{TiO}_{2}$

\section{SEM and TEM}

The morphology of the $1 \% \mathrm{~N}-\mathrm{TiO}_{2}$ catalyst was determined using the SEM at amplification of $50 \mu \mathrm{m}$ as depicted on Fig. 4(a). The particulate size was approximated to be around $8 \sim 13 \mathrm{~nm}$, with a spherical shaped as depicted on Fig 4(b) on a higher magnification of $10 \mathrm{~nm}$. That is because some aggregation has occurred during the synthesis process. The TEM image also depicts the nanocrystal lattice fringes of $\mathrm{TiO}_{2}$ (101) crystallographic planes with lattice space of $0.36 \mathrm{~nm}$ when measured with image $\mathbf{J}$ software as shown in the insert of Fig 4 (b)
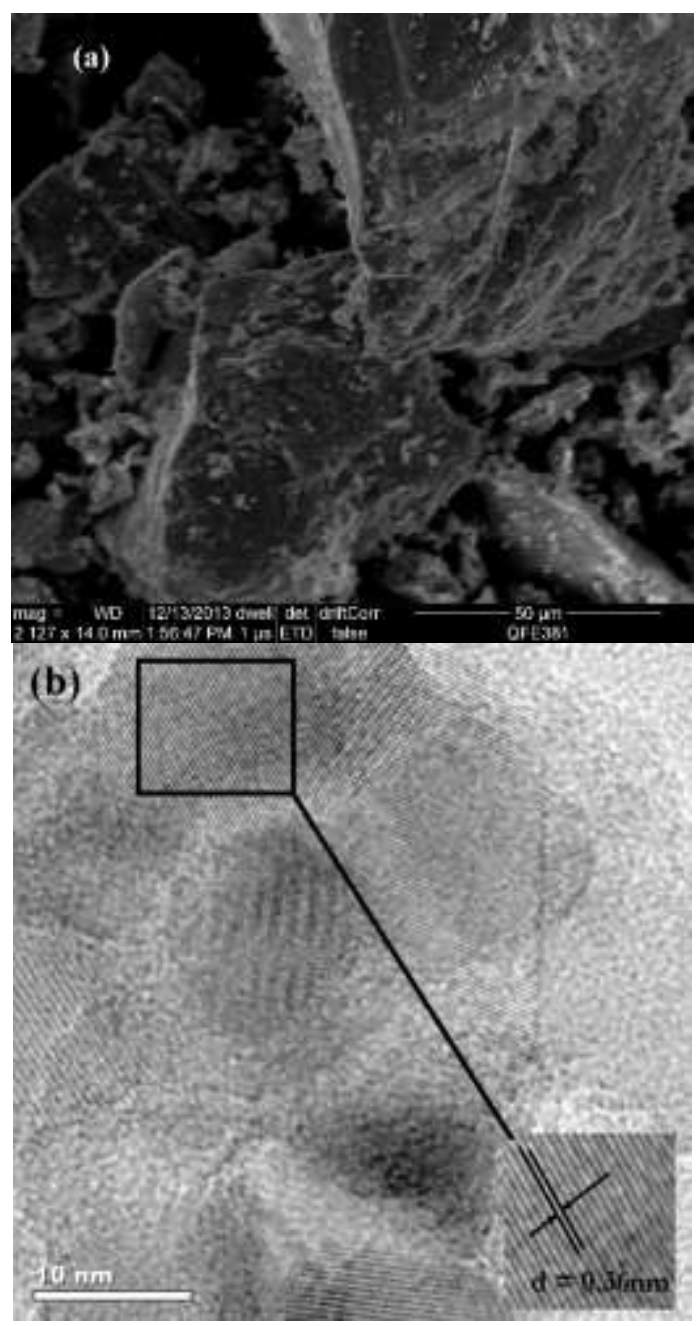

Fig. 4: (a) SEM and (b) TEM image $1 \mathrm{~N}-\mathrm{TiO}_{2}$

\section{TGA measurements}

The TGA result showed the weight loss of the sample during calcination. Two step weight loss was observed. In the first step the main weight loss is between 60 and $86^{\circ} \mathrm{C}$ which corresponds to the removal of volatiles solvents like n-hexane, methanol and 1-butanol that were used in the preparation of the catalyst. The second step is a weight loss between 124 to $302^{\circ} \mathrm{C}$ which is due to adsorbed water, and loss accompanied with collapse of interagglomerate and escape of trace moiety during the phase transformation from anatase to rutile (Hermann, 2005)

\section{Diffuse reflectance UV-Vis measurement}

The UV-vis absorption spectra of the as-synthesized samples in Fig. 6. Doping Titania with $\mathrm{N}$ greatly enhanced the absorption of $\mathrm{N}_{-} \mathrm{TiO}_{2}$ sample in the UV-vis spectrum and effectively extended the absorption edge into visible light region. Such an absorbance enhancement in the visible-light range was 
consistent with the yellowish colour characteristic of the $\mathrm{N}-\mathrm{TiO}_{2}$ sample. The $\mathrm{N}_{-} \mathrm{TiO}_{2}$ sample exhibited two kinds of characteristic light absorption edges in the DRS curves of the N$\mathrm{TiO}_{2}$ sample. One was in UV region attributable to the intrinsic band gap of $\mathrm{TiO}_{2}$, while the other originated from the new energy level in the forbidden band of $\mathrm{TiO}_{2}$ formed by $\mathrm{N}$ doping. The sample exhibit a shift in the optical absorption edge toward the visible region on $\mathrm{N}-\mathrm{TiO}_{2}$, which indicated that the nitrogen species occupied some oxygen positions in the lattice of $\mathrm{N}-\mathrm{TiO}_{2}$.

The band gap was calculated using plank's equation

Band gap energy $(\mathrm{E})=\frac{h c}{\lambda}$.

But where $\mathrm{c}=$ speed of light $=3 \times 10^{8} \mathrm{~m} / \mathrm{s}$

and $\lambda=$ wavelength $=451 \mathrm{~nm}$

Therefore,

Bandgap $=2.75 \mathrm{eV}$

Therefore, the optical band gap is $2.75 \mathrm{eV}$ for the $\mathrm{N}-\mathrm{TiO}_{2}$ nanoparticles. The narrow band gap, caused by localized Nitrogen $2 p$ states in the band structure in the form of substitutional and interstitial $\mathrm{N}$ states, allowed the enhancement of visible light photocatalytic activity.

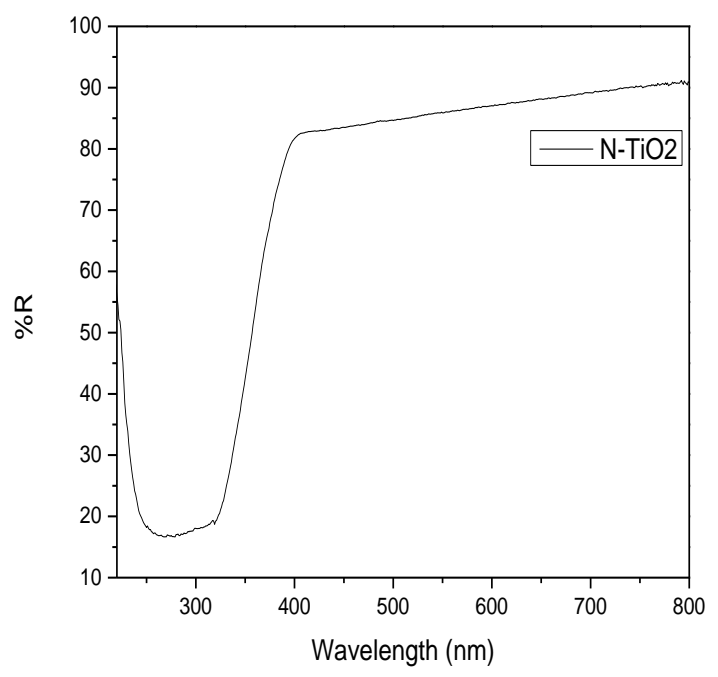

Fig. 6 Diffuse reflectance UV-Vis spectra

Photocatalytic degradation of methylene blue dye by $1 \%$ wtN-TiO

The first 20 minutes of irradiation of the methylene blue solution with the catalyst acts effectively with $1 \% \mathrm{wtN}-\mathrm{TiO}_{2}$ efficiently degrading compare to $3 \% \mathrm{wtN}-\mathrm{TiO}_{2}, 5 \% \mathrm{wtN}-\mathrm{TiO}_{2}$ and pure$\mathrm{TiO}_{2}$, but for the rest of the time i.e. from 40 minutes to 60 minutes there was a gradual reduction on the $\mathrm{N}-\mathrm{TiO}_{2}$ photocatalyst activity compared to the other three catalyst. Between 60-80 minutes of the Ultraviolet light irradiation all the $\mathrm{N}-\mathrm{TiO}_{2}$ photocatalyst were almost deactivating. From this observation it can be infer that above 80 minutes of irradiation the catalyst would deactivate completely. This drawback using ammonia as $\mathrm{N}$ precursors is its chemisorbed nature on $\mathrm{TiO}_{2}$ surface, which might cover the photoactive sites that served as Lewis bases to capture photo-induced holes; this is detrimental to the oxidative degradation. That might diminish the overall photoactive promoting effect of the $\mathrm{N}$ doping. which shows constancy in the rate constants of the reaction for each prepared photocatalyst in the degradation of methylene blue dye for the 80 minutes of irradiation with respect to first order equation. This means that the pseudo-first order kinetic of dye removal is acceptable for this photocatalytic process. The photoactivity of the catalysts follow the trend $1 \% \mathrm{wtN}-\mathrm{TiO}_{2}>3 \% \mathrm{wtN}-$ $\mathrm{TiO}_{2}>5 \% \mathrm{wtN}-\mathrm{TiO}_{2}>$ Pure- $\mathrm{TiO}_{2}$.

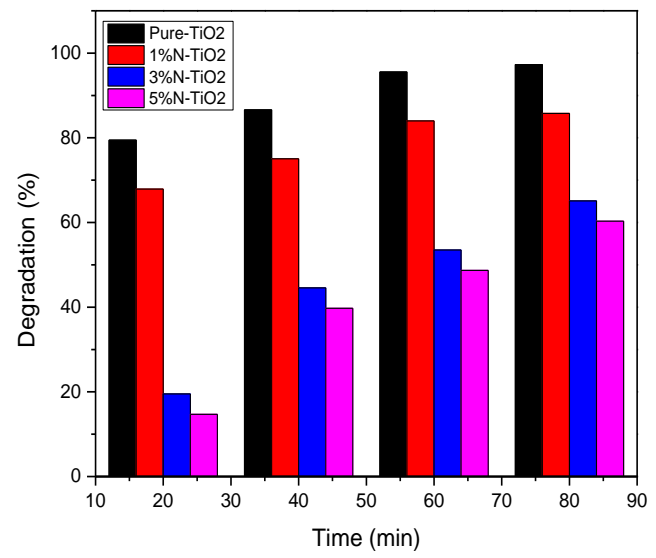

Fig. 7 Rate of photocatalytic degradation of methylene blue dye using $1 \%$ wt, $3 \%$ wt, $5 \%$ wtN-TiO2 under UV-light irradiation

Kinetics of methylene blue dye degradation.

According to the kinetics studies shown in Fig. 8 i.e. the plot of $-\ln \mathrm{C} / \mathrm{Co}$ of $\mathrm{MB}$ versus irradiation time for photocatalytic degradation using $1 \% \mathrm{wtN}-\mathrm{TiO}_{2}, 3 \% \mathrm{wtN}-\mathrm{TiO}_{2}, 5 \% \mathrm{wtN}-\mathrm{TiO}_{2}$ and $\mathrm{PURE}-\mathrm{TiO}_{2}$ photocatalyst reactions. The mineralization of the methylene blue dye obeys a linear pattern with a good precision in all cases. Which shows constancy in the rate constants of the reaction for each prepared photocatalyst in the degradation of methylene blue dye for the 80 minutes of irradiation with respect to first order equation. This means that the pseudo-first order kinetic of dye removal kinetic is acceptable for all photocatalytic processes [28], but comparison of the lines rate constants $0.049,0.0287,0.0143$ and $0.0118 \mathrm{~s}^{-1}$ corresponding to $1 \% \mathrm{NTiO}_{2}, 3 \% \mathrm{~N}-\mathrm{TiO}_{2}, 5 \% \mathrm{~N}-\mathrm{TiO}_{2}$ and PURE$\mathrm{TiO}_{2}$ photocatalysed reaction which is the apparent rate constant show that $1 \% \mathrm{~N}-\mathrm{TiO}_{2}>3 \% \mathrm{~N}-\mathrm{TiO}_{2}>5 \% \mathrm{~N}-\mathrm{TiO}_{2}>\mathrm{PURE}-\mathrm{TiO}_{2}$ catalysed reaction photoactivity follow the trend indicated in the photocatalytic degradation at the same conditions. 


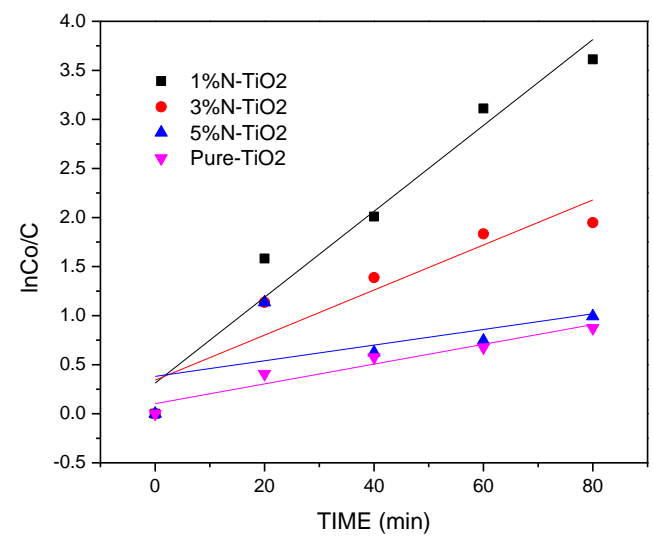

Fig. 8: Kinetics of photocatalytic degradation of methylene blue dye

\section{CONCLUSION}

Conclusively, the nitrogen content significantly affects the properties of doped $\mathrm{TiO}_{2}$ photocatalyst. Optimally $1 \% \mathrm{wt} \mathrm{N}$ $\mathrm{TiO}_{2}$ effectively controls the particle growth and agglomeration, surface area, band gap, etc. The $\mathrm{TiO}_{2}$ doped with $1 \%$ by weight nitrogen was the efficient photocatalyst showing best physicochemical properties (stable anatase phase with smallest crystallite and particle size, narrow particle size distribution, uniform morphology of particles and highest surface area) and efficiently photocatalytic activity in methylene blue dye.

\section{REFERENCES}

Asahi R., Morikawa, T., Ohwaki, T., Aoki K., Taga Y. (2001). Visible light photocatalysis in N-doped titanium dioxide. $J$. of natural science, Vol 293 (1), pp 269-271.

Borgarello E., Kiwi, J., Graetzel, M., Pelizette E., Visca M. (1982). Visible light induced water cleavage in colloidal solutions of chromium doped-titanium dioxide particles. Journal of American Chemical Society, ACS publication, Vol. 104(11), pp. 2996-3002.

Chakraborty, R., Roychowdhury, D. (2013). Fish bone derived natural hydroxyapatite-supported copper acid catalyst: Taguchi optimization of semi batch oleic esterification. Chemical engineering journal, Elsevier. Vol 215-216, pp. 491-499.

C, Chao. (2014). Visible light photocatalyst for synthesis of fine organic chemicals on supported nanostructure. Queensland University of Technology.

Chen, D., Jiang, Z., Gang, J., Wang, Q. (2007). Carbon and nitrogen co-doped titanium dioxide with enhanced visible-light photocatalytic activity. Industrial and Chemistry Research, ACS Publication, Vol. 46(1), pp. 2741-2746.

Choi, W., Termi A., Hoffman, M. R. (1994). The role of metal ion dopants in quantum-sized $\mathrm{TiO}_{2}$ : correlation between photo reactivity and charge carrier recombination dynamics. Journal of Physical Chemistry, Vol. 98, pp. 13669-13679.
Corro, G., Fierro J. L, Odilon V. C., G. (2005). Strong improvement on $\mathrm{CH}_{4}$ oxidation over $\mathrm{Pt} / \mathrm{Al}_{2} \mathrm{O}_{3}$ catalysts. Catalysis. Communication, Vol. 6 pp 287.

Hermann J.M. (2005). Heterogeneous photocatalysis: state of the art and present application in honor of Pr. R.L. Burwell Jr. (1912-2003), Former Head of Ipatieff Laboratories, Northwestern University, Evanston III. Topics in catalysis. Vol 34(1-4), pp. 49-65.

Hong Y, C., Bang C, U., Shin, D.H., Uhm, H.S. (2005). Band gab narrowing of titanium dioxide by nitrogen doping in atmospheric microwave plasma. Chemistry and Physics letter, Elsevier, Vol. 413, pp. 454-457.

Hosseinnia, A., Keyanpour-Rad, M. (2010). Photocatalytic degradation of organic dyes with different chromorphores by synthesize $\mathrm{TiO}_{2}$ particles. World Applied Science Journal, Vol. 8, pp. 32-39

Klosek S., and Raftery D. (2001). Visible light driven V-shape titanium dioxide photocatalyst and photooxidation of ethanol. Journal of physical chemistry, ACS publication Vol. 105(14), pp. 2815-2819.

Lang, A. R., Zimcik, P., Miletin, M. (2009). Dyes and pigments: New Research. Nova Science, ed (1), New York, pp. 44-45.

Mahvi A.H., Ghanbarian, M. Nasseri, S. Khairi, A. (2009). Mineralization and Discoloration of Textile Wastewater by $\mathrm{TiO}_{2}$ nanoparticles. Journal of Desalination, Elsevier, Vol. 239(13),309-316.

Nishizawa K., Okada M., Watanaba E. (2014). New preparation method of visible light responsive titanium dioxide photocatalytic films. Journal of materials science and applications, Scientific Research Publication. Vol. 5(3), pp. 112-123.

Parker S.P. (1984). McGraw-Hill. Dictionary of Chemistry. McGraw-Hill (1).

Serway R. A and Jewette J. W. (2018). Physics for Scientist and Engineers with Modern Physics. New York: Cengage learning 9(1).

Shan Z., Wang W., Lin X., Ding H., Huang F. (2008). Photocatalytic degradation of organic dyes on visible-light responsive photocatalyst $\mathrm{PbBiO} 2 \mathrm{Br}$. Journal of Solid-State Chemistry Elsevier. Vol 181(6), 1361-1366.

Song, Y.L., Li, J.T., Bai, B. (2010). $\mathrm{TiO}_{2}$-assisted photodegradation of Direct Blue 78 in aqueous solution in sunlight. Journal of Water, Air \& Soil Pollution, Vol. 213(1-4), pp 311-317

Suda, Y., Kawasaki H., Ueda, T., Oshima, T. (2005). Preparation of nitrogen-doped titanium oxide thin film using a PLD method as parameters of target material and nitrogen concentration ratio in nitrogen/oxygen gas mixture. Thin solid films, Elsevier, Vol. 475, pp. 337-341. 
Vazquez C. O., Cruz L. A., Bautista C. L. M., Bautista-H. A., Yilleng M.T, Gimba C.E, Ndukwe G.I, Bugaje I.M, Rooney Torres M. L. M., Wohn L.S., (2010), Synthesis of $\mathrm{TiO}_{2}$ using D.W, Manyar H.G (2018) Batch to continuous photocatalytic different hydrolysis catalysts and doped with $\mathrm{Zn}$ for efficient degradation of phenol using $\mathrm{TiO}_{2}$ and Au-Pd nanoparticles degradation of aqueous phase pollutants under. Journal supported on $\mathrm{TiO}_{2}$. Journal of Environmental Chemical Colloidal Interface, Research on Intermediates, Vol 36(1), pp Engineering 6, 6382-6389

103-113

Viswanathan, B., Krishnamurthy, K. R. (2012). Nitrogen incorporation in $\mathrm{TiO}_{2}$ : does it make a visible light photoactive material. International journal of photoenergy. Vol. 2012, pp.10.

Wang, S. (2008). A comparative study of Fenton and Fentonlike reaction kinetics in decolourization of wastewater. Journal of Dyes and Pigments, Elsevier, Vol. 76 (3), pp. 714-720.

Wang H., Lewis J. P. (2005). Effect of dopant on photoactivity in carbon-doped $\mathrm{TiO}_{2}$. Journal of Physics Condensed Matter, Vol. 17(1), pp. 209-213.

Xie, M. Z, Jing, L. Q., Zhou, J., Lin, J. S., Fu H. G. (2010). Synthesis of nanocrystalline anatase $\mathrm{TiO}_{2}$ by one-pot two-phase separated hydrolysis-solvothermal processes and its high activity for photo- catalytic degradation of rhodamine B. Journal of Hazardous Materials, Elsevier, Vol 176(1-3), pp.139145 .
Zabek, P., Kisch, H. (2010). Polyol-derived carbon-modified Titania for visible light photocatalysis. Journal of Coordination Chemistry, Taylor and Frances, Vol. 63, pp. 2715-2726.

Zhang Q., Gao L., Guo J., (2000), Effects of calcination on the photocatalytic properties of nanosized $\mathrm{TiO}_{2}$ powders prepared by $\mathrm{TiCl}_{4}$ hydrolysis. Applied Catalysis. B: Environmental Vol. (26): 207-215.

Zhang, M., Wu, J., Hou, J, Yang, J. (2013). Molybdenum and nitrogen co-doped titanium dioxide nanotube arrays with enhanced visible light photocatalytic activity. Science of advanced materials, American scientific Publisher, Vol. 5(6), pp. 535-541.

Zhao, W., Dong F., Wu Z. (2008). Characterization and photocatalytic activities of $\mathrm{C}, \mathrm{N}$ and $\mathrm{S}$ co-doped titanium dioxide with 1-dimentional nanostructure prepared by the nanoconfinement effect. J. nanotechnology, Vol. 19, pp. 365607-365616. 